\title{
The Costs of Depression
}

\author{
Ronald C. Kessler, PhDa \\ Professor of Health Care Policy, Department of Health Care Policy, Harvard Medical School
}

\section{Brief summary}

Data are reviewed on the societal costs of major depressive disorder (MDD). Early-onset MDD is found to predict difficulties in subsequent role transitions, including low educational attainment, high risk of teen child-bearing, marital disruption, and unstable employment. Among people with specific social and productive roles, MDD is found to predict significant decrements in role functioning (e.g., low marital quality, low work performance, low earnings). MDD is also associated with elevated risk of onset, persistence, and severity of a wide range of chronic physical disorders as well as with increased early mortality due to an even wider range of physical disorders and to suicide. Although effectiveness trials show that expanded MDD treatment can reverse many of these adverse effects, only a minority of people with MDD receives treatment and the quality of treatment is unacceptably low among the majority of those in treatment.

\section{Keywords}

Absenteeism; costs of illness; disability; illness burden; impairment; major depressive disorder

Major depression is a commonly occurring, seriously impairing, and often recurrent mental disorder. ${ }^{1,2}$ The World Health Organization ranks major depressive disorder (MDD) as the $4^{\text {th }}$ leading cause of disability worldwide ${ }^{3}$ and projects that by 2020 it will be the second leading cause due to currently unexplained increasing prevalence in recent cohorts. ${ }^{4}$ Although data on the prevalence and costs of MDD do not exist for most countries, psychiatric epidemiological surveys of the general population, students, and primary care patients have been carried out in many developed countries as well as in an increasing

(C) 2011 Elsevier Inc. All rights reserved.

${ }^{a}$ Corresponding author for proofs and reprints: Ronald C. Kessler, PhD, Department of Health Care Policy, Harvard Medical School, 180 Longwood Avenue, Boston, MA 02115, (617) 432-3587, (617) 432-3588 (fax), kessler@hcp.med.harvard.edu (email).

This report was prepared in conjunction with the author's participation in the World Health Organization World Mental Health (WMH) Survey Initiative. WMH is supported by the United States National Institute of Mental Health (R01MH070884), the John D. and Catherine T. MacArthur Foundation, the Pfizer Foundation, the US Public Health Service (R13-MH066849, R01-MH069864, and R01 DA016558), the Fogarty International Center (FIRCA R03-TW006481), the Pan American Health Organization, the Eli Lilly \& Company Foundation, Ortho-McNeil Pharmaceutical, Inc., GlaxoSmithKline, Sanofi Aventis and Bristol-Myers Squibb. A complete list of WMH publications can be found at http://www.hcp.med.harvard.edu/wmh/.

Dr. Kessler has been a consultant for AstraZeneca, Analysis Group, Bristol-Myers Squibb, Cerner-Galt Associates, Eli Lilly \& Company, GlaxoSmithKline Inc., HealthCore Inc., Health Dialog, Integrated Benefits Institute, John Snow Inc., Kaiser Permanente, Matria Inc., Mensante, Merck \& Co, Inc., Ortho-McNeil Janssen Scientific Affairs, Pfizer Inc., Primary Care Network, Research Triangle Institute, Sanofi-Aventis Groupe, Shire US Inc., SRA International, Inc., Takeda Global Research \& Development, Transcept Pharmaceuticals Inc., and Wyeth-Ayerst; has served on advisory boards for Appliance Computing II, Eli Lilly \& Company, Mindsite, Ortho-McNeil Janssen Scientific Affairs, Plus One Health Management and Wyeth-Ayerst; and has had research support for his epidemiological studies from Analysis Group Inc., Bristol-Myers Squibb, Eli Lilly \& Company, EPI-Q, GlaxoSmithKline, Johnson \& Johnson Pharmaceuticals, Ortho-McNeil Janssen Scientific Affairs., Pfizer Inc., Sanofi-Aventis Groupe, and Shire US, Inc.

Publisher's Disclaimer: This is a PDF file of an unedited manuscript that has been accepted for publication. As a service to our customers we are providing this early version of the manuscript. The manuscript will undergo copyediting, typesetting, and review of the resulting proof before it is published in its final citable form. Please note that during the production process errors may be discovered which could affect the content, and all legal disclaimers that apply to the journal pertain. 
number of developing countries. The results of these surveys are reviewed in this chapter. The paper begins with an overview of information on the descriptive epidemiology of major depression (prevalence, age-of-onset, course, comorbidity) and then focuses primarily on data documenting the individual and societal costs of depression.

Before turning to the review, it is noteworthy that a number of the largest epidemiological surveys of major depression focused on major depressive episodes (MDE) rather than major depressive disorders (MDD). The difference between the two is that MDE includes depressive episodes that occur as part of bipolar disorder while MDD excludes bipolar depression. As the vast majority of lifetime MDE is MDD, the difference between the two is not of great importance when examining lifetime disorders. However, as bipolar depression is considerably more persistent than non-bipolar depression, ${ }^{5}$ the proportion of MDE cases due to bipolar depression increases as the time frame of assessment decreases, making it important to distinguish MDE from MDD in examining current prevalence and correlates. We consequently focus in the current report on MDD, but report data on MDE when they are the only data available for some major studies.

\section{BASIC DESCRIPTIVE EPIDEMIOLOGY}

\section{Prevalence}

Weissman et al. ${ }^{6}$ published the first cross-national data on the prevalence of MDD, using the same methods as, the landmark US Epidemiologic Catchment Area (ECA) Study. ${ }^{7}$ Lifetime prevalence estimates in these surveys were in the range 1.5-19.0\%, with a midpoint of $9.4 \%$ and generally higher rates in high income than lower income countries. Twelve-month prevalence estimates were in the range $0.8-5.8 \%$, with a midpoint of $3.7 \%$. Subsequent studies $^{8}$ using a diagnostic interview developed by the World Health Organization (WHO) explicitly for cross-national comparative research found prevalence estimates of MDD that were very similar to those in the earlier ECA-based surveys, again finding higher rates in high income than lower income countries. ${ }^{8}$ Moussavi et al. ${ }^{9}$ more recently reported data on the 12-month prevalence of MDE (ICD-10 criteria) from the massive ( $n=245,404$ respondents) WHO World Health Survey (WHS), a 60-country survey designed to assess the recent prevalence and impairment of a wide range of health problems in every region of the world (http://www.who.int/healthinfo/survey/whsresults/en/index.html). Major depression was the one mental disorder included in the WHS. The 12-month prevalence of major depression was $3.2 \%$ and between $9.3 \%$ and $23.0 \%$ among participants with a chronic condition. Bromet et al. ${ }^{10}$ more recently reported data on the 12-month and lifetime prevalence of MDE from the 18-country WHO World Mental Health (WMH) Surveys ( $\mathrm{n}=$ 89,037). Mean lifetime and 12-month prevalence estimates of DSM-IV MDE were 14.6\% and $5.5 \%$ in high income countries compared to $11.1 \%$ and $5.9 \%$ in low-middle income countries.

The wide cross-national variation in prevalence estimates and generally elevated rates in high income countries might reflect cross-national differences in the threshold for defining clinically significant depression in diagnostic interviews. However, if that was the case, we would expect that depression detected in countries with the lowest estimated prevalence would be the most severe cases, resulting in high impairment rates, and that reports of core depressive symptoms would be more similar across countries than estimates of disorder prevalence. Neither of these expectations was borne out, though, when they were examined in the WMH data, adding indirect support to a substantive interpretation of the crossnational differences in MDE. But why do these prevalence differences exist? Differences in stress exposure, in reactivity to stress, and in endogenous depression unrelated to environmental provoking factors are all possibilities. On one level it seems counter-intuitive that people in high income countries would experience more stress than those in low-middle 
income countries. However, it has been suggested that depression is to some extent an illness of affluence. ${ }^{11} \mathrm{~A}$ related argument is that income inequality, which is for the most part greater in high than low-middle income countries, promotes a wide variety of chronic conditions that includes depression. ${ }^{12}$ While further analyses of existing epidemiological data might shed some light on these perspectives, such analyses have not yet been carried out.

\section{Course of illness}

Few large-scale longitudinal general population studies of MDD exist, but clinical studies show that a substantial proportion of people who seek treatment for major depression have a chronic-recurrent course of illness. ${ }^{13,14}$ Subtyping these people is complicated by the fact that chronic depression subtypes are poorly understood. ${ }^{15}$ The community survey finding that lifetime prevalence is two-three times that of 12-month prevalence suggests that between a third and a half of lifetime cases have recurrent episodes in a given year. However, long-term longitudinal studies also show that some people with lifetime MDD fail to report their history of depression in cross-section studies. ${ }^{16,17} \mathrm{We}$ would expect this recall failure to be lower in the WMH surveys because of special probes used for lifetime recall, ${ }^{18}$ but it would nonetheless be prudent to consider the 12-month-to-lifetime prevalence ratios in the WMH surveys upper-bound estimates on persistence and WMH lifetime prevalence estimates lower-bound estimates on true lifetime prevalence because of likely recall failure in retrospective reports of lifetime prevalence.

\section{THE COSTS OF MAJOR DEPRESSION}

\section{Life course role incumbency, timing, and transitions}

Given their typically early AOO, mental disorders might be expected to have adverse effects on critical developmental transitions, such as educational attainment and timing of marriage. A number of epidemiological studies have examined these effects, with a focus on four domains: education, marital timing and stability, childbearing, and occupation.

Education-Several studies show early-onset mental disorders associated termination of education. ${ }^{19-26}$ While disruptive behavior disorders and bipolar disorder tend to have the strongest associations in these studies, MDD also is significantly associated with a roughly $60 \%$ elevated odds of failure to complete secondary school than otherwise comparable youth in high income countries.

Marital timing and stability-Several studies have examined associations of pre-marital mental disorders with subsequent marriage. ${ }^{27-29}$ Early-onset mental disorders predict low probability of ever marrying, but are either positively associated ${ }^{28}$ or unrelated ${ }^{27}$ with early (before age 18) marriage, which is known to be associated with a number of adverse outcomes, and negatively associated with on-time and late marriage, which are known to be associated with a number of benefits (e.g., financial security, social support). These associations are largely the same for men and women and across countries. MDD is one of the most important of these pre-marital mental disorders. A separate set of studies has shown that pre-marital history of mental disorders predicts divorce, ${ }^{30,31}$ again with associations quite similar for husbands and wives across all countries and MDD among the most important disorders in this regard. ${ }^{27}$

Teen childbearing - We are aware of only one study that examined the association between child-adolescent mental disorder and subsequent teen child bearing. ${ }^{32} \mathrm{MDD}$ and a number of other early-onset mental disorders were significant predictors of increased teen 
childbearing. Disaggregation found that the overall associations were due to disorders predicting increased sexual activity but not decreased use of contraception.

Employment status-Although depression is known to be associated with unemployment, most research on this association has emphasized the impact of job loss on depression rather than depression as a risk factor for job loss. ${ }^{33}$ A recent analysis from the WMH surveys documented the latter association by showing that history of mental disorders as of the age of completing schooling predicted current (at the time of interview) unemployment and work disability. ${ }^{34}$ However, these associations were only significant in high income countries, raising the possibility that MDD becomes more detrimental to work performance as the substantive complexity of work increases.

\section{Role performance}

A considerably larger amount of research has been carried out on the associations of mental disorders with various aspects of role performance, with a special focus on marital quality, work performance, and financial success.

Marital functioning-It has long been known that marital dissatisfaction and discord are strongly related to depressive symptoms (e.g., ${ }^{35,36}$ ), with an average correlation between marital dissatisfaction and depressive symptoms of approximately $\mathrm{r}=.4$ across studies and very similar patterns for men and women. ${ }^{37}$ Longitudinal studies show that the association is bidirectional, ${ }^{38,39}$ but with a stronger time-lagged association of marital discord predicting depressive symptoms than vice versa. ${ }^{40}$ Fewer studies have considered the effects of clinical depression on marital functioning, ${ }^{41-43}$ but those studies consistently document significant adverse effects.

Considerable research documents that both perpetration of and victimization by physical violence in marital relationships are significantly associated with depression. ${ }^{44}$ While these studies have generally focused on presumed mental health consequences of relationship violence, ${ }^{45-47}$ a growing body of research has more recently suggested that marital violence is partly a consequence of pre-existing mental disorders. ${ }^{48-51}$ Indeed, longitudinal studies consistently find that pre-marital history of mental disorders, including depression, predict subsequent marital violence perpetration ${ }^{49,52}$ and victimization. ${ }^{44,50,51,53}$ However, few of these studies adjusted for comorbidity. A recent study in the WMH surveys ${ }^{54}$ found that the association between premarital history of MDD and subsequent marital violence disappears after controls are introduced for disruptive behavioral disorders and substance use disorders, suggesting that depression might be a risk marker rather than a causal risk factor.

Parental functioning-A number of studies have documented significant associations of both maternal ${ }^{55}$ and paternal ${ }^{56}$ depression with negative parenting behaviors. These associations are found throughout the age range of children, but most pronounced for the parents of young children. Although only an incomplete understanding exists of pathways, both laboratory and naturalistic studies of parent-infant micro-interactions have documented subtle ways in which parent depression leads to maladaptive interactions that impede infant affect regulation and later child development. ${ }^{57}$

Days out of role-Considerable research has examined days out of role associated with various physical and mental disorders in an effort to produce data on comparative disease burden for health policy planning purposes ${ }^{58,59}$ These studies typically find that MDD is associated with among the highest number of days out of role at the societal level of any physical or mental disorder due to its combination of comparatively high prevalence and comparatively strong individual-level association. ${ }^{60-62}$ In the WMH surveys, for example, 
62,971 respondents across 24 countries were assessed for a wide range of common physical and mental disorders as well as for days out of role in the 30 days before interview. ${ }^{63} \mathrm{MDD}$ was associated with $5.1 \%$ of all days out of role, the fourth highest population attributable risk proportion of all the disorders considered (exceeded only by headache/migraine, other chronic pain conditions, and cardiovascular disorders) and by far the largest among the mental disorder. A number of epidemiological surveys in the US have estimated the workplace costs of either MDE or MDD on absenteeism and low work performance (often referred to as presenteeism).${ }^{64-67}$ All these studies found that MDE and MDD significantly predict overall lost work performance. Several studies attempted to estimate the annual salary-equivalent human capital value of these losses. These estimates were in the range $\$ 30.1$ billion $^{66}$ to $\$ 51.5$ billion. $^{64}$

Financial success-One of most striking aspects of the impairment associated with MDD is that the personal earnings and household income of people with MDD are substantially lower than those of people without depression. ${ }^{68-73}$ However, it is unclear whether depression is primariry a cause, consequence, or both in these associations due to the possibility of reciprocal causation between income-earnings and MDD. ${ }^{74}$ Causal effects of low income on depression have been documented in quasi-experimental studies of job loss. ${ }^{33}$ Time series analyses have also documented aggregate associations between unemployment rates and suicide rates. ${ }^{75}$ Previous studies of the effects of mental disorders on reductions in income have not controlled for these reciprocal effects, making the size of the adverse effects of depression on income-earnings uncertain. One way to sort out this temporal order would be to take advantage of the fact that depression often starts in childhood or adolescence and use prospective epidemiological data to study long-term associations between early-onset disorders and subsequent income-earnings. Several such studies exist, all of them suggesting that depression in childhood-adolescence predicts reduced income-earnings in adulthood. ${ }^{76-77}$

Comparative impairments-A number of community surveys, most of them carried out in the US, have examined the comparative effects of diverse diseases on various aspects of role functioning. ${ }^{59,} 62,78-81 \mathrm{MDE}$ was included in a number of these studies and the results typically showed that musculoskeletal disorders and MDE were associated with the highest levels of disability at the individual level among all commonly occurring disorders assessed. The most compelling study of this sort outside the US was based on fifteen national surveys carried out as part of the WMH surveys. ${ }^{82}$ Disorder-specific disability scores were compared across people who experienced each of ten chronic physical disorders and ten mental disorders in the year before interview. MDD and bipolar disorder (BPD) were the mental disorders most often rated severely impairing in both developed and developing countries. None of the physical disorders considered had impairment levels as high as those for MDD or BPD despite the fact that the physical disorders included such severe conditions as cancer, diabetes, and heart disease. Nearly all the higher mental-than-physical ratings were statistically significant at the .05 level. Comparable results were obtained when analyses focused exclusively on sub-samples of cases in treatment and when comparisons were restricted to respondents who had both disorders in a given pair (e.g., respondents who had both MDD and cancer or both MDD and heart disease).

Another set of surveys examined comparative decrements in perceived health associated with a wide range of disorders. ${ }^{9,}, 83,84$ MDD was the focus of two such studies. The first study was part of the WHO World Health Surveys of nearly one-quarter of a million respondents across 60 countries..$^{9}$ A consistent pattern was found in these surveys across countries and socio-demographic subgroups within countries for MDD to be associated with a larger decrement in perceived health than any of the four physical disorders compared with it (angina, arthritis, asthma, diabetes). The second study was part of the WMH surveys, 
where MDD was compared with 18 other physical (e.g., cancer, cardiovascular disorders, diabetes) and mental (e.g., BPD, panic disorder, post-traumatic stress disorder) disorders in predicting a summary measure of perceived health. ${ }^{85} \mathrm{MDD}$ was one of the three disorders associated with the highest decrements in perceived health, the other two being severe insomnia and neurological disorders (epilepsy, Parkinson's disease, multiple sclerosis).

\section{Morbidity and mortality}

It is now well established that MDD is significantly associated with a wide variety of chronic physical disorders, including arthritis, asthma, cancer, cardiovascular disease, diabetes, hypertension, chronic respiratory disorders, and a variety of chronic pain conditions. ${ }^{86-94}$ Although most of the data documenting these associations comes from clinical samples in the US, similar data also exist from community epidemiological surveys carried out throughout the world. ${ }^{95}, 96$ These associations have considerable individual and public health significance and can be thoughts of as representing costs of depression in at least two ways. First, to the extent that MDD is a causal risk factor, it leads to an increased prevalence of these physical disorders, with all their associated financial costs, impairments, and increased mortality risk. Evidence about MDD as a cause of these physical disorders is spotty, though, although we know from meta-analyses of longitudinal studies that MDD is a consistent predictor of the subsequent first onset of coronary artery disease, ${ }^{97,}, 98$ stroke, 99 diabetes, ${ }^{100}$ heart attacks,${ }^{101,102}$ and certain types of cancer. ${ }^{103}$ A number of biologically plausible mechanisms have been proposed to explain the prospective associations of MDD with these disorders. ${ }^{104-108}$ These include a variety of poor health behaviors known to be linked to MDD, such as elevated rates of smoking and drinking, ${ }^{109}$ obesity, ${ }^{110}$ low compliance with treatment regimens, ${ }^{111}, 112$ and a variety of biological dysregulations, such as hypothalamic-pituitary-adrenal hyperactivity and impaired immune function. ${ }^{113}$

Based on these observations, there is good reason to believe that MDD might be a causal risk factor for at least some chronic physical disorders. Second, even if depression is more a consequence than a cause of chronic physical disorders, as it appears to be for some disorders based on stronger prospective associations of depression onset subsequent to, rather than before, onset of the physical disorder, comorbid depression is often associated with a worse course of the physical disorder. ${ }^{114-116}$ A number of reasons could be involved here, but one of the most consistently documented is that depression is often associated with non-adherence to treatment regimens. ${ }^{112,117,118}$ Based on these considerations, it should not be surprising that MDD is associated with significantly elevated risk of early death. ${ }^{104,} 106,119$ This is true partly because people with MDD have high suicide risk, ${ }^{120-122}$ but also because depression is associated with elevated risk of the many types of disorders noted above. MDD is also associated with elevated mortality risk among people with certain kinds of disorders as part of a larger pattern of associations of MDD with disorder severity. There has been particular interest in MDD as a risk factor for cardiovascular mortality due to heart attack and stroke among people with cardiovascular disease (CVD). ${ }^{123-126}$ Indeed, a number of interventions have been developed to detect and treat depression among people with CVD in an effort to prolong life, although the results of these studies have so far been only modest. ${ }^{127}$

\section{DISCUSSION}

The data reported here show clearly that major depression is a commonly occurring and burdensome disorder. The high prevalence, early age of onset, and high persistence of MDD in the many different countries where epidemiological surveys have been administered confirm the high worldwide importance of depression. Although evidence is not definitive that MDD plays a causal role in its associations with the many adverse outcomes reviewed here, there is clear evidence that depression has causal effects on a number of important 
mediators, making it difficult to assume anything other than that depression has strong causal effects on many dimensions of burden. These results have been used to argue for the likely cost-effectiveness of expanded depression treatment from a societal perspective. ${ }^{128}$ Two separate large-scale randomized workplace depression treatment effectiveness trials have been carried out in the US to evaluate the cost-effectiveness of expanded treatment from an employer perspective. ${ }^{129,130}$ Both trials had positive returns-on-investment to employers. A substantial expansion of worksite depression care management programs has occurred in the US subsequent to the publication of these trials. ${ }^{131}$ Yet the proportion of people with depression who receive treatment remains low in the US and even lower in other parts of the world. A recent US study found that only about half of workers with MDD received treatment in the year of interview and that fewer than half of treated workers received treatment consistent with published treatment guidelines. ${ }^{132}$ Although the treatment rate was higher for more severe cases, even those with severe MDD often failed to receive treatment. ${ }^{133}$ The WMH surveys show that treatment rates are even lower in many other developed countries and consistently much lower in developing countries. ${ }^{134}$ Less information is available on rates of depression treatment among patients with chronic physical disorders, but available evidence suggests that expanded treatment could be of considerable value. ${ }^{135}$ Randomized controlled trials are needed to expand our understanding of the effects of detection and treatment of depression among people in treatment for chronic physical disorders. In addition, controlled effectiveness trials with long-term follow-ups are needed to increase our understanding of the effects of early MDD treatment interventions on changes in life course role trajectories, role performance, and onset of secondary physical disorders.

\section{References}

1. Spijker J, Graaf R, Bijl RV, et al. Functional disability and depression in the general population. Results from the Netherlands Mental Health Survey and Incidence Study (NEMESIS). Acta Psychiatr Scand. 2004; 110:208-14. [PubMed: 15283741]

2. Üstün TB, Ayuso-Mateos JL, Chatterji S, et al. Global burden of depressive disorders in the year 2000. Br J Psychiatry. 2004; 184:386-92. [PubMed: 15123501]

3. Murray CJ, Lopez AD. Evidence-based health policy--lessons from the Global Burden of Disease Study. Science. 1996; 274:740-3. [PubMed: 8966556]

4. Murray, CJL.; Lopez, AD. The Global Burden of Disease: a comprehensive assessment of mortality and disability from diseases, injuries and risk factors in 1990 and projected to 2020. Harvard University Press; 1996.

5. Merikangas KR, Jin R, He JP, et al. Prevalence and correlates of bipolar spectrum disorder in the World Mental Health Survey Initiative. Arch Gen Psychiatry. 2011; 68:241-51. [PubMed: 21383262]

6. Weissman MM, Bland RC, Canino GJ, et al. Cross-national epidemiology of major depression and bipolar disorder. JAMA. 1996; 276:293-9. [PubMed: 8656541]

7. Robins, LN.; Regier, DA., editors. Psychiatric disorders in America: the Epidemiologic Catchment Area Study. New York: The Free Press; 1991.

8. Andrade L, Caraveo-Anduaga JJ, Berglund P, et al. The epidemiology of major depressive episodes: results from the International Consortium of Psychiatric Epidemiology (ICPE) Surveys. Int J Methods Psychiatr Res. 2003; 12:3-21. [PubMed: 12830306]

9. Moussavi S, Chatterji S, Verdes E, et al. Depression, chronic diseases, and decrements in health: results from the World Health Surveys. Lancet. 2007; 370:851-8. [PubMed: 17826170]

10. Bromet E, Andrade LH, Hwang I, et al. Cross-national epidemiology of DSM-IV major depressive episode. BMC Med. 2011; 9:90. [PubMed: 21791035]

11. Koplewicz HS, Gurian A, Williams K. The era of affluence and its discontents. J Am Acad Child Adolesc Psychiatry. 2009; 48:1053-5. [PubMed: 19855219]

Psychiatr Clin North Am. Author manuscript; available in PMC 2013 March 1. 
12. Wilkinson RG, Pickett KE. Income inequality and population health: a review and explanation of the evidence. Soc Sci Med. 2006; 62:1768-84. [PubMed: 16226363]

13. Hardeveld F, Spijker J, De Graaf R, et al. Prevalence and predictors of recurrence of major depressive disorder in the adult population. Acta Psychiatr Scand. 2010; 122:184-91. [PubMed: 20003092]

14. Torpey DC, Klein DN. Chronic depression: update on classification and treatment. Curr Psychiatry Rep. 2008; 10:458-64. [PubMed: 18980728]

15. Benazzi F. Various forms of depression. Dialogues Clin Neurosci. 2006; 8:151-61. [PubMed: 16889102]

16. Moffitt TE, Caspi A, Taylor A, et al. How common are common mental disorders? Evidence that lifetime prevalence rates are doubled by prospective versus retrospective ascertainment. Psychol Med. 2010; 40:899-909. [PubMed: 19719899]

17. Patten SB, Williams JV, Lavorato DH, et al. Recall of recent and more remote depressive episodes in a prospective cohort study. Soc Psychiatry Psychiatr Epidemiol. 2011

18. Knäuper B, Cannell CF, Schwarz N, et al. Improving accuracy of major depression age-of-onset reports in the US National Comorbidity Survey. Int J Methods Psychiatr Res. 1999; 8:39-48.

19. Breslau J, Lane M, Sampson N, et al. Mental disorders and subsequent educational attainment in a US national sample. J Psychiatr Res. 2008; 42:708-16. [PubMed: 18331741]

20. Breslau J, Miller E, Joanie Chung WJ, et al. Childhood and adolescent onset psychiatric disorders, substance use, and failure to graduate high school on time. J Psychiatr Res. 2011; 45:295-301. [PubMed: 20638079]

21. Kessler RC, Foster CL, Saunders WB, et al. Social consequences of psychiatric disorders, I: Educational attainment. Am J Psychiatry. 1995; 152:1026-32. [PubMed: 7793438]

22. Lee S, Tsang A, Breslau J, et al. Mental disorders and termination of education in high-income and low- and middle-income countries: epidemiological study. Br J Psychiatry. 2009; 194:411-7. [PubMed: 19407270]

23. McLeod JD, KK. Childhood emotional and behavioral problems and educational attainment. Am Sociological Rev. 2004; 69:636-58.

24. Porche MV, Fortuna LR, Lin J, et al. Childhood trauma and psychiatric disorders as correlates of school dropout in a national sample of young adults. Child Dev. 2011; 82:982-98. [PubMed: 21410919]

25. Vaughn MG, Wexler J, Beaver KM, et al. Psychiatric correlates of behavioral indicators of school disengagement in the United States. Psychiatr Q. 2011; 82:191-206. [PubMed: 20957435]

26. Woodward LJ, Fergusson DM. Life course outcomes of young people with anxiety disorders in adolescence. J Am Acad Child Adolesc Psychiatry. 2001; 40:1086-93. [PubMed: 11556633]

27. Breslau J, Miller E, Jin R, et al. A multinational study of mental disorders, marriage, and divorce. Acta Psychiatr Scand. 2011 (e-publication ahead of print).

28. Forthofer MS, Kessler RC, Story AL, et al. The effects of psychiatric disorders on the probability and timing of first marriage. J Health Soc Behav. 1996; 37:121-32. [PubMed: 8690874]

29. Whisman MA, Tolejko N, Chatav Y. Social consequences of personality disorders: probability and timing of marriage and probability of marital disruption. J Pers Disord. 2007; 21:690-5. [PubMed: 18072869]

30. Butterworth P, Rodgers B. Mental health problems and marital disruption: is it the combination of husbands and wives' mental health problems that predicts later divorce? Soc Psychiatry Psychiatr Epidemiol. 2008; 43:758-63. [PubMed: 18478168]

31. Kessler RC, Walters EE, Forthofer MS. The social consequences of psychiatric disorders, III: probability of marital stability. Am J Psychiatry. 1998; 155:1092-6. [PubMed: 9699699]

32. Kessler RC, Berglund PA, Foster CL, et al. Social consequences of psychiatric disorders, II: Teenage parenthood. Am J Psychiatry. 1997; 154:1405-11. [PubMed: 9326823]

33. Dooley D, Fielding J, Levi L. Health and unemployment. Annu Rev Public Health. 1996; 17:44965. [PubMed: 8724235]

34. Kawakami N, Abdulghani EA, Alonso J, et al. Early-life mental disorders and adult household income in the World Mental Health Surveys. Biol Psychiatry. in press.

Psychiatr Clin North Am. Author manuscript; available in PMC 2013 March 1. 
35. Culp LN, Beach SRH. Marriage and depressive symptoms: the role and bases of self-esteem differ by gender. Psychol Women Quart. 1998; 22:647-63.

36. Whisman MA. Marital dissatisfaction and psychiatric disorders: results from the National Comorbidity Survey. J Abnorm Psychol. 1999; 108:701-6. [PubMed: 10609435]

37. Whisman, SA. SRH Beach. Marital and family processes in depression: a scientific foundation for clinical practice. Washington, DC: American Psychological Association; 2001. The association between depression and marital dissatisfaction; p. 3-24.

38. Mamun AA, Clavarino AM, Najman JM, et al. Maternal depression and the quality of marital relationship: a 14-year prospective study. J Womens Health (Larchmt). 2009; 18:2023-31. [PubMed: 20044866]

39. Whisman MA, Uebelacker LA. Prospective associations between marital discord and depressive symptoms in middle-aged and older adults. Psychol Aging. 2009; 24:184-9. [PubMed: 19290750]

40. Proulx CM, Helms HM, Buehler C. Marital quality and personal well-being: a meta-analysis. J Marriage Fam. 2007; 69:576-93.

41. Coyne JC, Thompson R, Palmer SC. Marital quality, coping with conflict, marital complaints, and affection in couples with a depressed wife. J Fam Psychol. 2002; 16:26-37. [PubMed: 11915407]

42. Kronmuller KT, Backenstrass M, Victor D, et al. Quality of marital relationship and depression: results of a 10-year prospective follow-up study. J Affect Disord. 2011; 128:64-71. [PubMed: 20674034]

43. Pearson KA, Watkins ER, Kuyken W, et al. The psychosocial context of depressive rumination: ruminative brooding predicts diminished relationship satisfaction in individuals with a history of past major depression. Br J Clin Psychol. 2010; 49:275-80. [PubMed: 20109277]

44. Stith SM, Smith DB, Penn CE, et al. Intimate partner physical abuse perpetration and victimization risk factors: A meta-analytic review. Aggress Viol Behav. 2004; 10:65-98.

45. Afifi TO, MacMillan H, Cox BJ, et al. Mental health correlates of intimate partner violence in marital relationships in a nationally representative sample of males and females. J Interpers Violence. 2009; 24:1398-417. [PubMed: 18718882]

46. Kim HK, Laurent HK, Capaldi DM, et al. Men's aggression toward women: a 10-year panel study. J Marriage Fam. 2008; 70:1169-87. [PubMed: 19122790]

47. Renner LM. Intimate partner violence victimization and parenting stress: assessing the mediating role of depressive symptoms. Violence Against Women. 2009; 15:1380-401. [PubMed: 19809099]

48. Kessler RC, Molnar BE, Feurer ID, et al. Patterns and mental health predictors of domestic violence in the United States: results from the National Comorbidity Survey. Int J Law Psychiatry. 2001; 24:487-508. [PubMed: 11521422]

49. Lorber MF, O'Leary KD. Predictors of the persistence of male aggression in early marriage. J Fam Viol. 2004; 19:329-38.

50. O'Leary KD, Tintle N, Bromet EJ, et al. Descriptive epidemiology of intimate partner aggression in Ukraine. Soc Psychiatry Psychiatr Epidemiol. 2008; 43:619-26. [PubMed: 18360731]

51. Riggs DS, Caulfield MB, Street AE. Risk for domestic violence: factors associated with perpetration and victimization. J Clin Psychol. 2000; 56:1289-316. [PubMed: 11051060]

52. Fang X, Massetti GM, Ouyang L, et al. Attention-deficit/hyperactivity disorder, conduct disorder, and young adult intimate partner violence. Arch Gen Psychiatry. 2010; 67:1179-86. [PubMed: 21041619]

53. Lehrer JA, Buka S, Gortmaker S, et al. Depressive symptomatology as a predictor of exposure to intimate partner violence among US female adolescents and young adults. Arch Pediatr Adolesc Med. 2006; 160:270-6. [PubMed: 16520446]

54. Miller E, Breslau J, Petukhova M, et al. Premarital mental disorders and physical violence in marriage: cross-national study of married couples. Br J Psychiatry. 2011

55. Lovejoy MC, Graczyk PA, O'Hare E, et al. Maternal depression and parenting behavior: a metaanalytic review. Clin Psychol Rev. 2000; 20:561-92. [PubMed: 10860167]

56. Wilson S, Durbin CE. Effects of paternal depression on fathers' parenting behaviors: a metaanalytic review. Clin Psychol Rev. 2010; 30:167-80. [PubMed: 19926376] 
57. Tronick E, Reck C. Infants of depressed mothers. Harv Rev Psychiatry. 2009; 17:147-56. [PubMed: 19373622]

58. Alonso J, Angermeyer MC, Bernert S, et al. Disability and quality of life impact of mental disorders in Europe: results from the European Study of the Epidemiology of Mental Disorders (ESEMeD) project. Acta Psychiatr Scand Suppl. 2004:38-46. [PubMed: 15128386]

59. Merikangas KR, Ames M, Cui L, et al. The impact of comorbidity of mental and physical conditions on role disability in the US adult household population. Arch Gen Psychiatry. 2007; 64:1180-8. [PubMed: 17909130]

60. Collins JJ, Baase CM, Sharda CE, et al. The assessment of chronic health conditions on work performance, absence, and total economic impact for employers. J Occup Environ Med. 2005; 47:547-57. [PubMed: 15951714]

61. Munce SE, Stansfeld SA, Blackmore ER, et al. The role of depression and chronic pain conditions in absenteeism: results from a national epidemiologic survey. J Occup Environ Med. 2007; 49:1206-11. [PubMed: 17993924]

62. Wang PS, Beck A, Berglund P, et al. Chronic medical conditions and work performance in the health and work performance questionnaire calibration surveys. J Occup Environ Med. 2003; 45:1303-11. [PubMed: 14665817]

63. Alonso J, Petukhova M, Vilagut G, et al. Days out of role due to common physical and mental conditions: results from the WHO World Mental Health surveys. Mol Psychiatry. 2010 (epublication ahead of print).

64. Greenberg PE, Kessler RC, Birnbaum HG, et al. The economic burden of depression in the United States: how did it change between 1990 and 2000? J Clin Psychiatry. 2003; 64:1465-75. [PubMed: 14728109]

65. Kessler RC, Akiskal HS, Ames M, et al. Prevalence and effects of mood disorders on work performance in a nationally representative sample of U.S. workers. Am J Psychiatry. 2006; 163:1561-8. [PubMed: 16946181]

66. Stewart WF, Ricci JA, Chee E, et al. Cost of lost productive work time among US workers with depression. JAMA. 2003; 289:3135-44. [PubMed: 12813119]

67. Wang PS, Simon G, Kessler RC. The economic burden of depression and the cost-effectiveness of treatment. Int J Methods Psychiatr Res. 2003; 12:22-33. [PubMed: 12830307]

68. Ford E, Clark C, McManus S, et al. Common mental disorders, unemployment and welfare benefits in England. Public Health. 2010; 124:675-81. [PubMed: 21035154]

69. Insel TR. Assessing the economic costs of serious mental illness. Am J Psychiatry. 2008; 165:6635. [PubMed: 18519528]

70. Kessler RC, Heeringa S, Lakoma MD, et al. Individual and societal effects of mental disorders on earnings in the United States: results from the national comorbidity survey replication. Am J Psychiatry. 2008; 165:703-11. [PubMed: 18463104]

71. Levinson D, Lakoma MD, Petukhova M, et al. Associations of serious mental illness with earnings: results from the WHO World Mental Health surveys. Br J Psychiatry. 2010; 197:114-21. [PubMed: 20679263]

72. Marcotte DE, Wilcox-Gok V. Estimating the employment and earnings costs of mental illness: recent developments in the United States. Soc Sci Med. 2001; 53:21-7. [PubMed: 11386306]

73. McMillan KA, Enns MW, Asmundson GJ, et al. The association between income and distress, mental disorders, and suicidal ideation and attempts: findings from the collaborative psychiatric epidemiology surveys. J Clin Psychiatry. 2010; 71:1168-75. [PubMed: 20441719]

74. Muntaner C, Eaton WW, Miech R, et al. Socioeconomic position and major mental disorders. Epidemiol Rev. 2004; 26:53-62. [PubMed: 15234947]

75. Jones L. The health consequences of economic recessions. J Health Soc Policy. 1991; 3:1-14. [PubMed: 10116577]

76. Smith JP, Smith GC. Long-term economic costs of psychological problems during childhood. Soc Sci Med. 2010; 71:110-5. [PubMed: 20427110]

77. Goodman A, Joyce R, Smith JP. The long shadow cast by childhood physical and mental problems on adult life. Proc Natl Acad Sci U S A. 2011; 108:6032-7. [PubMed: 21444801]

Psychiatr Clin North Am. Author manuscript; available in PMC 2013 March 1. 
78. Kessler RC, Greenberg PE, Mickelson KD, et al. The effects of chronic medical conditions on work loss and work cutback. J Occup Environ Med. 2001; 43:218-25. [PubMed: 11285869]

79. Lerner D, Allaire SH, Reisine ST. Work disability resulting from chronic health conditions. J Occup Environ Med. 2005; 47:253-64. [PubMed: 15761321]

80. Stewart WF, Ricci JA, Chee E, et al. Lost productive work time costs from health conditions in the United States: results from the American Productivity Audit. J Occup Environ Med. 2003; 45:1234-46. [PubMed: 14665809]

81. Verbrugge LM, Patrick DL. Seven chronic conditions: their impact on US adults' activity levels and use of medical services. Am J Public Health. 1995; 85:173-82. [PubMed: 7856776]

82. Ormel J, Petukhova M, Chatterji S, et al. Disability and treatment of specific mental and physical disorders across the world. Br J Psychiatry. 2008; 192:368-75. [PubMed: 18450663]

83. Alonso J, Ferrer M, Gandek B, et al. Health-related quality of life associated with chronic conditions in eight countries: results from the International Quality of Life Assessment (IQOLA) Project. Qual Life Res. 2004; 13:283-98. [PubMed: 15085901]

84. Manuel DG, Schultz SE, Kopec JA. Measuring the health burden of chronic disease and injury using health adjusted life expectancy and the Health Utilities Index. J Epidemiol Community Health. 2002; 56:843-50. [PubMed: 12388577]

85. Alonso J, Vilagut G, Chatterji S, et al. Including information about co-morbidity in estimates of disease burden: results from the World Health Organization World Mental Health Surveys. Psychol Med. 2011; 41:873-86. [PubMed: 20553636]

86. Anderson RJ, Freedland KE, Clouse RE, et al. The prevalence of comorbid depression in adults with diabetes: a meta-analysis. Diabetes Care. 2001; 24:1069-78. [PubMed: 11375373]

87. Buist-Bouwman MA, de Graaf R, Vollebergh WAM, et al. Comorbidity of physical and mental disorders and the effect on work-loss days. Acta Psychiatr Scand. 2005; 111:436-43. [PubMed: 15877710]

88. Chapman DP, Perry GS, Strine TW. The vital link between chronic disease and depressive disorders. Prev Chronic Dis. 2005; 2:A14. [PubMed: 15670467]

89. Derogatis LR, Morrow GR, Fetting J, et al. The prevalence of psychiatric disorders among cancer patients. JAMA. 1983; 249:751-7. [PubMed: 6823028]

90. Dew, MA. Psychiatric disorder in the context of physical illness. In: Dohrenwend, BP., editor. Adversity, Stress and Psychopathology. New York: Oxford University Press; 1998.

91. McWilliams LA, Cox BJ, Enns MW. Mood and anxiety disorders associated with chronic pain: an examination in a nationally representative sample. Pain. 2003; 106:127-33. [PubMed: 14581119]

92. Nemeroff CB, Musselman DL, Evans DL. Depression and cardiac disease. Depress Anxiety. 1998; 8 (Suppl 1):71-9.

93. Ortega AN, Feldman JM, Canino G, et al. Co-occurrence of mental and physical illness in US Latinos. Soc Psychiatry Psychiatr Epidemiol. 2006; 41:927-34. [PubMed: 17013767]

94. Wells KB, Golding JM, Burnam MA. Chronic medical conditions in a sample of the general population with anxiety, affective, and substance use disorders. Am J Psychiatry. 1989; 146:14406. [PubMed: 2817115]

95. Scott KM, Bruffaerts R, Tsang A, et al. Depression-anxiety relationships with chronic physical conditions: results from the World Mental Health Surveys. J Affect Disord. 2007; 103:113-20. [PubMed: 17292480]

96. Von Korff, MR.; Scott, KM.; Gureje, O. Global perspectives on mental-physical comorbidity in the WHO World Mental Health Surveys. Cambridge University Press; 2009.

97. Van der Kooy K, van Hout H, Marwijk H, et al. Depression and the risk for cardiovascular diseases: systematic review and meta analysis. Int J Geriatr Psychiatry. 2007; 22:613-26. [PubMed: 17236251]

98. Wulsin LR, Singal BM. Do depressive symptoms increase the risk for the onset of coronary disease? A systematic quantitative review. Psychosom Med. 2003; 65:201-10. [PubMed: 12651987]

99. Ohira T, Iso H, Satoh S, et al. Prospective study of depressive symptoms and risk of stroke among japanese. Stroke. 2001; 32:903-8. [PubMed: 11283390]

Psychiatr Clin North Am. Author manuscript; available in PMC 2013 March 1. 
100. Carnethon MR, Kinder LS, Fair JM, et al. Symptoms of depression as a risk factor for incident diabetes: findings from the National Health and Nutrition Examination Epidemiologic Follow-up Study, 1971-1992. Am J Epidemiol. 2003; 158:416-23. [PubMed: 12936896]

101. Pratt LA, Ford DE, Crum RM, et al. Depression, psychotropic medication, and risk of myocardial infarction. Prospective data from the Baltimore ECA follow-up. Circulation. 1996; 94:3123-9. [PubMed: 8989119]

102. Scherrer JF, Virgo KS, Zeringue A, et al. Depression increases risk of incident myocardial infarction among Veterans Administration patients with rheumatoid arthritis. Gen Hosp Psychiatry. 2009; 31:353-9. [PubMed: 19555796]

103. Gross AL, Gallo JJ, Eaton WW. Depression and cancer risk: 24 years of follow-up of the Baltimore Epidemiologic Catchment Area sample. Cancer Causes Control. 2010; 21:191-9. [PubMed: 19885645]

104. Carney RM, Freedland KE, Miller GE, et al. Depression as a risk factor for cardiac mortality and morbidity: a review of potential mechanisms. J Psychosom Res. 2002; 53:897-902. [PubMed: 12377300]

105. Cohen S, Rodriquez MS. Pathways linking affective disturbances and physical disorders. Health Psychol. 1995; 14:374-80. [PubMed: 7498107]

106. Cuijpers P, Schoevers RA. Increased mortality in depressive disorders: a review. Curr Psychiatry Rep. 2004; 6:430-7. [PubMed: 15538991]

107. Katon W, Ciechanowski P. Impact of major depression on chronic medical illness. J Psychosom Res. 2002; 53:859-63. [PubMed: 12377294]

108. Stapelberg NJ, Neumann DL, Shum DH, et al. A topographical map of the causal network of mechanisms underlying the relationship between major depressive disorder and coronary heart disease. Aust N Z J Psychiatry. 2011; 45:351-69. [PubMed: 21500954]

109. Davis L, Uezato A, Newell JM, et al. Major depression and comorbid substance use disorders. Curr Opin Psychiatry. 2008; 21:14-8. [PubMed: 18281835]

110. Cizza G. Major depressive disorder is a risk factor for low bone mass, central obesity, and other medical conditions. Dialogues Clin Neurosci. 2011; 13:73-87. [PubMed: 21485748]

111. Schlenk EA, Dunbar-Jacob J, Engberg S. Medication non-adherence among older adults: a review of strategies and interventions for improvement. J Gerontol Nurs. 2004; 30:33-43. [PubMed: 15287325]

112. Ziegelstein RC, Fauerbach JA, Stevens SS, et al. Patients with depression are less likely to follow recommendations to reduce cardiac risk during recovery from a myocardial infarction. Arch Intern Med. 2000; 160:1818-23. [PubMed: 10871976]

113. Kiecolt-Glaser JK, Glaser R. Depression and immune function: central pathways to morbidity and mortality. J Psychosom Res. 2002; 53:873-6. [PubMed: 12377296]

114. Gillen R, Tennen H, McKee TE, et al. Depressive symptoms and history of depression predict rehabilitation efficiency in stroke patients. Arch Phys Med Rehabil. 2001; 82:1645-9. [PubMed: 11733876]

115. Mancuso CA, Rincon M, McCulloch CE, et al. Self-efficacy, depressive symptoms, and patients' expectations predict outcomes in asthma. Med Care. 2001; 39:1326-38. [PubMed: 11717574]

116. Peyrot M, Rubin RR. Levels and risks of depression and anxiety symptomatology among diabetic adults. Diabetes Care. 1997; 20:585-90. [PubMed: 9096984]

117. Breitbart W, Rosenfeld B, Pessin H, et al. Depression, hopelessness, and desire for hastened death in terminally ill patients with cancer. JAMA. 2000; 284:2907-11. [PubMed: 11147988]

118. Cluley S, Cochrane GM. Psychological disorder in asthma is associated with poor control and poor adherence to inhaled steroids. Respir Med. 2001; 95:37-9. [PubMed: 11207015]

119. Wulsin LR, Vaillant GE, Wells VE. A systematic review of the mortality of depression. Psychosom Med. 1999; 61:6-17. [PubMed: 10024062]

120. Bostwick JM, Pankratz VS. Affective disorders and suicide risk: a reexamination. Am J Psychiatry. 2000; 157:1925-32. [PubMed: 11097952]

121. Moller HJ. Suicide, suicidality and suicide prevention in affective disorders. Acta Psychiatr Scand Suppl. 2003:73-80. [PubMed: 12956819]

Psychiatr Clin North Am. Author manuscript; available in PMC 2013 March 1. 
122. Rihmer Z. Suicide risk in mood disorders. Curr Opin Psychiatry. 2007; 20:17-22. [PubMed: 17143077]

123. Barth J, Schumacher M, Herrmann-Lingen C. Depression as a risk factor for mortality in patients with coronary heart disease: a meta-analysis. Psychosom Med. 2004; 66:802-13. [PubMed: 15564343]

124. Gump BB, Matthews KA, Eberly LE, et al. Depressive symptoms and mortality in men: results from the Multiple Risk Factor Intervention Trial. Stroke. 2005; 36:98-102. [PubMed: 15569872]

125. Lesperance F, Frasure-Smith N, Talajic M, et al. Five-year risk of cardiac mortality in relation to initial severity and one-year changes in depression symptoms after myocardial infarction. Circulation. 2002; 105:1049-53. [PubMed: 11877353]

126. van Melle JP, de Jonge P, Spijkerman TA, et al. Prognostic association of depression following myocardial infarction with mortality and cardiovascular events: a meta-analysis. Psychosom Med. 2004; 66:814-22. [PubMed: 15564344]

127. Thombs BD, de Jonge P, Coyne JC, et al. Depression screening and patient outcomes in cardiovascular care: a systematic review. JAMA. 2008; 300:2161-71. [PubMed: 19001627]

128. Wang PS, Patrick A, Avorn J, et al. The costs and benefits of enhanced depression care to employers. Arch Gen Psychiatry. 2006; 63:1345-53. [PubMed: 17146009]

129. Rost K, Smith JL, Dickinson M. The effect of improving primary care depression management on employee absenteeism and productivity. A randomized trial. Med Care. 2004; 42:1202-10. [PubMed: 15550800]

130. Wang PS, Simon GE, Avorn J, et al. Telephone screening, outreach, and care management for depressed workers and impact on clinical and work productivity outcomes: a randomized controlled trial. JAMA. 2007; 298:1401-11. [PubMed: 17895456]

131. Rost K, Marshall D, Shearer B, et al. Depression care management: can employers purchase improved outcomes? Depress Res Treat. 2011; 2011:942519. [PubMed: 21738872]

132. Kessler RC, Merikangas KR, Wang PS. The prevalence and correlates of workplace depression in the national comorbidity survey replication. J Occup Environ Med. 2008; 50:381-90. [PubMed: 18404010]

133. Birnbaum HG, Kessler RC, Kelley D, et al. Employer burden of mild, moderate, and severe major depressive disorder: mental health services utilization and costs, and work performance. Depress Anxiety. 2010; 27:78-89. [PubMed: 19569060]

134. Wang PS, Aguilar-Gaxiola S, Alonso J, et al. Use of mental health services for anxiety, mood, and substance disorders in 17 countries in the WHO world mental health surveys. Lancet. 2007; 370:841-50. [PubMed: 17826169]

135. Katon W, Lin EH, Kroenke K. The association of depression and anxiety with medical symptom burden in patients with chronic medical illness. Gen Hosp Psychiatry. 2007; 29:147-55.

[PubMed: 17336664] 